IRA-International Journal of Management \& Social Sciences

ISSN 2455-2267; Vol.04, Issue 01 (2016)

Institute of Research Advances

http://research-advances.org/index.php/RAJMSS

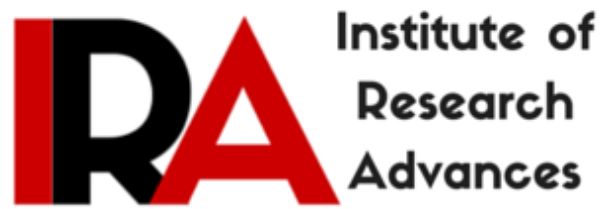

\title{
An Investigation of Low Volatility Anomaly in Indian Stock Market
}

\author{
${ }^{1}$ Sitaram Pandey, \\ Research Scholar, \\ Department of Commerce \& Management, \\ Vinoba Bhave University, Hazaribag, Jharkhand. \\ ${ }^{2}$ Dr. Amitava Samanta, \\ Assistant Professor, \\ Department of Commerce \& Management, \\ Vinoba Bhave University, Hazaribag, Jharkhand.
}

DOI: http://dx.doi.org/10.21013/jmss.v4.n1.p6

\section{How to cite this paper:}

Pandey, S., \& Samanta, A. (2016). An Investigation of Low Volatility Anomaly in Indian Stock Market. IRA-International Journal of Management \& Social Sciences (ISSN 2455-2267), 4(1). doi:http://dx.doi.org/10.21013/jmss.v4.n1.p6

(C) Institute of Research Advances

\section{(cc) EY-No}

This works is licensed under a Creative Commons Attribution-Non Commercial 4.0 International License subject to proper citation to the publication source of the work.

Disclaimer: The scholarly papers as reviewed and published by the Institute of Research Advances (IRA) are the views and opinions of their respective authors and are not the views or opinions of the IRA. The IRA disclaims of any harm or loss caused due to the published content to any party. 


\section{ABSTRACT}

The objective of this paper is to investigate the presence of low volatility anomaly in Indian stock Market. Anomaly occurs due to the deviation in normal behavior of stocks with respect to risk-return relationship as suggested by CAPM theory. The low volatility anomaly means that portfolio of low volatility stocks provides better returns than the portfolio of high volatility stocks. The anomaly under study is one of the most common technical anomalies detected in various International markets but very few studies are there in Indian context. CAPM theory suggest that there is direct relationship between risk \& return but various empirical studies finds that portfolio of low volatility stocks outperforms portfolio of high volatility stocks. In this study, returns of volatility sorted portfolios are used to analyze the low volatility anomaly. The study uses constituent stocks of S\&P CNX 100 index of NSE. The data is taken from period January 2001 to December 2014. The results of this study did not found any significant low volatility anomaly in India rather results are supporting the CAPM model and thus found that high volatility quintile gives high returns in India and vice-versa.

Keywords: CAPM, Low volatility Anomaly, Sorted portfolio, Regression, CNX 100

JEL Classification: G02, G11, G12, G14

\subsection{Introduction}

Various researches have been done on asset pricing but still there is no any consensus regarding the relationship of variables affecting the return of an asset. However, some researchers are comparing return on an asset on the basis of its risk category but still the concept is unsatisfactory in terms of its results. But till date, CAPM model given by Sharpe (1964), Linter (1965) \& Black (1972) is successfully implemented to find return which explains direct relationship between risk and return but however in some studies it is found out that the CAPM model is not proving good and thus demonstrated that the market factor alone cannot explain the cross sectional variation in asset returns. Accordingly several market anomalies have been identified which has been categorized into calendar or fundamental anomalies. Calendar anomalies includes Day-of-the-Week effect, Week-of-the-Month effect, Semi-month effect, Intra-day etc. and fundamental anomalies includes size effect, earning-surprise effect, split effect, small-cap effect (low P/E stocks and small cap companies do better than index on an average), low beta effect etc. Calendar anomalies involve similar patterns in stock returns from year to year, month to month or in the days of the week. Anomaly indicates mispricing of an asset and its persistence for a well known period of time.

Asset Pricing Anomalies: There are four well-documented asset pricing anomalies. These effects are anomalous in that the CAPM prediction that a test of the time-series regression $\left.R_{i, t}-R_{f, t}\right)=\alpha_{i}+\beta_{i}$ ( $\left.R_{m, t}-R_{f, t}\right)+e_{i, t}$ will show $\alpha_{i}=0$ fails ( because the estimated alpha is statistically significantly different from zero).

- Value effect: Value stocks (those with high book value-to-market value ratios) tend to have higher expected returns than the CAPM prediction, and growth stocks (those with low book-tomarket ratios) have lower expected returns than the CAPM prediction. In an empirical test of CAPM, a portfolio that buys value stocks and short sells growth stocks has $\alpha_{i}>0$ ( this alpha is statistically significantly different than zero).

- Size effect: Small stocks(those with low market capitalization) tend to have higher expected returns than the CAPM prediction, and large stocks( those with high market capitalization) tend to have lower expected returns than the CAPM prediction. In an empirical test of CAPM, a portfolio that buys small stocks and short sells large stocks has $\alpha_{i}>0$.

- Momentum effect: Momentum stocks (those that have done well in the past year ) have higher expected returns than the CAPM prediction, and recent looser stocks(those that have done poorly 
in the past year) have lower expected returns than the CAPM prediction. In an empirical test of CAPM, a portfolio that buys recent winner stocks and short recent looser stocks has $\alpha_{i}>0$.

- Reversal effect: Long-run loser stocks(those that have done poorly in the past 3 to 5 years have higher expected returns than the CAPM prediction, and long-run winner stocks(those that have done well in the past 3 to 5 years) have lower expected returns than the CAPM prediction. In an empirical test of CAPM, a portfolio that buys long-run loser stocks and shorts long-run winner stocks has $\alpha_{i}>0$.

But still the low volatility anomaly is not well-documented yet so, In this paper we will focus our study on low risk anomaly; it is one of the most interesting anomalies as it is challenging the traditional asset pricing theory that securities with high risk gives higher expected return. Capital Asset Pricing Model (CAPM), the traditional asset pricing theory predicted the mean-variance efficiency of the market portfolio and the Efficient Market Hypothesis, which predicted that markets are informational efficient. Thus, securities with high risk should be provided with higher expected returns. But it was found in various studies done in foreign \& Indian context that the low volatility stocks outperforming high volatility stocks on an average over the time on risk-adjusted basis where risk is measured in terms of standard deviation or beta.

It does not matter whether we define our risk in terms of standard deviation or beta, when stocks are sorted into quintiles, the low risk portfolio significantly outperforms the portfolio of high risk securities, and this has been termed as low risk anomaly. Low risk anomaly makes it possible to have portfolios which give returns greater than the market portfolio with lower risk. The two investment strategies most commonly used to exploit risk anomaly are- 1) low volatility (LV) portfolio investing, and 2) Minimum variance (MV) portfolio investing. The present study employs low volatility investment strategy in which risk is measured by standard deviation of the returns of the selected stocks to explore the low volatility anomaly in Indian stock market.

\subsection{Review of Literature: Empirical Evidences of Low volatility Anomaly}

Many studies has documented for the last many years about the relationship between risk and return and found much more flatter than provided by CAPM in many studies done by Black(1972), Haugen \& Heins, (1975). Haugen and Heins pointed out that the relationship was not merely flat in their sample period but was actually inverted. Extending their analysis through 1990s, Fama and French (Fama \& French, 1992) also reported that the relationship was flat or even negative. Fama \& French later also documented three factor model and expanded the prediction of CAPM to include the value effect and size effect as additional risk factors and thereafter Chen, Roll and Ross formulate a five-factor model which uses factors that describes macroeconomic activity broadly.

Low volatility anomaly has been initiated by early work from Haugen and Baker (Haugen \& Baker, 1975). After this, many studies in US market (Chan, Karceski, \& Lakonishok, 1999), (Schawartz, 2000), (Jagannathan \& Ma, 2003) etc. reported both higher returns and lower realized risks for the minimum variance portfolio (MVP) versus a capitalization weighted benchmark (MWP).

Haugen and Heins(1975)(H\&H) produced a working paper covering the period from 1926 to 1971in which they addressed deficiencies in previous studies about the relationship between risk and realized return. The paper documented a negative relationship between risk and return in both the U.S. Stock Market and the U.S. Bond market.

Fama and French(1992) found in his paper " The cross-section of expected stock returns" that simple relation between $\beta$ and average return disappears during the period of 1963-1990. Their tests do not support the central prediction of the SLB model, that average stock returns are positively related to market $\beta$. 
Jagannathan and $\mathrm{Ma}(2003)$ find higher returns and lower risk for a U.S. minimum variance portfolio versus a capitalization-weighted benchmark.

Roger Clarke, Harvin de Silva, and Steven Thorley (2006) carried out an interesting study on the characteristics of minimum-variance (MV) portfolios and found that MV portfolios, based on the 1,000 largest U.S. stocks over the period 1968-2005 achieved a volatility reduction of about $25 \%$ while delivering comparable or even higher average returns than the broad market portfolio.

Blitz and Van Vliet (2007) presented that portfolios of stocks with the lowest historical volatility are associated with Sharpe-ratio improvements that are even greater than those documented by Clarke et al.(2006), and have a statistically significant positive alpha. They found that low beta stocks had higher returns than predicted while the reverse held for high beta stocks.

Ang, Hodrick , Xing and Zhang (2006, 2009) find that U.S. stocks with high volatility have abnormally low returns and later they found that stocks with past high idiosyncratic volatility have low future returns over 23 developed markets.

Carvalho , Xiao and Moulon (2012) examine alternatives to capitalization -weighted strategies in world markets and find that a minimum variance portfolio provides the greatest Sharpe ratio.

Baker and Haugen (2012) covered stocks of 21developed countries and 12 emerging markets over the time period of 1990 to 2011 and found that low-risk stocks outperform.

Pandey and Prachetas (2012) examined the risk anomaly on 51 stocks of NSE for a period of 12years from May 2000 to April 2012. The analysis gave higher average monthly rate of returns for low volatility stocks when compared with high volatility and market portfolios.

Rohan Rambhia and Mayank Joshipura (2012) studied Risk Anomaly in Indian Equity Market from the period January 2001 to June 2011 and found that the low volatility portfolio strategy gives a higher absolute return over a long period.

Sanjay Sehgal, Srividya Subramaniam , and Laurence Porteu DE LA (2012) studied Indian -market and disproved the traditional theory (i.e) higher the risk higher the return.

Vidisha Garg and Sahaj Wadhwa (2014) studied low volatility anomaly in India and found the results supportive of traditional theory and concluded that investors realize high returns only by bearing high risk.

Also, much evidence of research on the said anomalies is available for international markets but in India, there is a limited work regarding low risk anomaly has been done. Hence, the main objective of the present study is to find out the existence of above mentioned anomaly in Indian stock market.

\subsection{Research Objective}

The main objective of the study is to examine the existence of low risk anomaly in Indian stock market. This paper is divided into nine sections. The first section includes introduction of the topic, the second section includes review of literature, the third section discusses about objectives of the study, the fourth section tells about the data used for analysis, the fifth section tells about research methodology used for finding results, the sixth section tells about the result of empirical analysis done in the paper, the seventh section summarizes and concluded the paper, the eight section discussed the limitations of the study, the ninth section presents the practical implications of the study and the last section i.e. tenth section presented the references used in this paper. 


\subsection{Data}

Our sample includes the companies that form a part of S\&P CNX 100 Index. The sample companies chosen is representing $78 \%$ of the total trading activity and market capitalization of the stocks listed on NSE as on March 31, 2015. We use monthly closing share prices, adjusted for stock dividends, stock splits and rights issues, for the sample period from January 2001 to December 2014. Monthly share prices have been converted into monthly returns for the analysis of data. CNX 100 has been used to proxy market returns. The data has been taken from NSE website. The yield on 10-year government bond has been used as risk-free rate. The risk-free rate has been obtained from website of ministry of Finance.

\subsection{Research Methodology}

We are replicating the methodology for analysis as used by other researchers on the same topic. For the purpose of examining Low volatility anomaly, the analysis period of fourteen years, i.e. from January 2001to December 2014has been chosen. The risk of a stock is represented by its volatility, which is defined as the standard deviation of monthly returns over a period of 60 months, i.e. from January 2001 to December 2005. The 80 stocks are taken from CNX 200 whose data is available on NSE for the consideration of portfolio formation and these stocks are arranged in ascending order of their standard deviations and then divided into five portfolios. The composition of a portfolio changes every month depending on the standard deviation of the stocks in previous 60 months. Hence, for the first portfolio of January 2006, formation is over the 60-month period starting from January 2001 to December 2005. The price movements in this period are used to calculate the standard deviation. Portfolios have been rebalanced on every month on the basis of their standard deviations by assuming zero transaction costs in the process. The stocks are divided into five portfolios. Quintile 1 named as portfolio 1represents 20\% lowest standard deviation stocks, next $20 \%$ are kept in second quintile and so on. For each month, performance of a portfolio is measured as the simple average of returns of all the stocks in the portfolio for that month implying that the portfolios are equal- weighted portfolios. Portfolios have been constructed till December 2014 using rolling monthly iterations, and in total there are 110 iterations. Thus, we construct five portfolios, hold them for a month and then rebalance the portfolios in the next month. We finally end up with 110 monthly return values for each of the quintile portfolios.

We will also check Capital Asset Pricing Model (CAPM) on the returns of the volatility sorted portfolios. For this excess returns on each volatility portfolio are regressed on the market factor. We test CAPM using the following market model:

$$
\left(r_{p t}-r_{f t}\right)=\alpha+\beta\left(r_{m t}-r_{f t}\right)+e_{t}
$$

Where $\left(r_{p t}-r_{f t}\right)=$ Excess return on volatility sorted portfolios,

$\left(r_{m t}-r_{f t}\right)=$ Excess return on the market factor,

and $\alpha, \beta$ are the estimated parameters.

\subsection{Empirical Analysis and Results}

Monthly rebalancing gives 110 monthly return observations for each quintile. Table I gives the average of portfolios excess returns $\left(r_{p t}-r_{f t}\right)$. It is cleared from the table I and the graph I that high volatility sorted portfolio i.e. Portfolio 5 gives high return and low volatility sorted portfolio i.e Portfolio 1 gives low return. 
Table I: Mean Portfolio Excess Returns

\begin{tabular}{|l|l|l|l|l|l|l|}
\hline Portfolio & $\begin{array}{l}\text { Portfolio 1 } \\
\text { (P1) }\end{array}$ & $\begin{array}{l}\text { Portfolio2 } \\
\text { (P2) }\end{array}$ & $\begin{array}{l}\text { Portfolio3 } \\
\text { (P3) }\end{array}$ & $\begin{array}{l}\text { Portfolio4 } \\
\text { (P4) }\end{array}$ & $\begin{array}{l}\text { Portfolio5 } \\
\text { (P5) }\end{array}$ & $\begin{array}{l}\text { Difference } \\
\text { between(P1)\&( P5) }\end{array}$ \\
\hline $\begin{array}{l}\text { Mean } \\
\text { Excess } \\
\text { Return }\end{array}$ & 0.01960 & 0.02197 & 0.02228 & 0.02706 & 0.03774 & 0.0181 \\
\hline
\end{tabular}

Figure I: Mean Excess Return

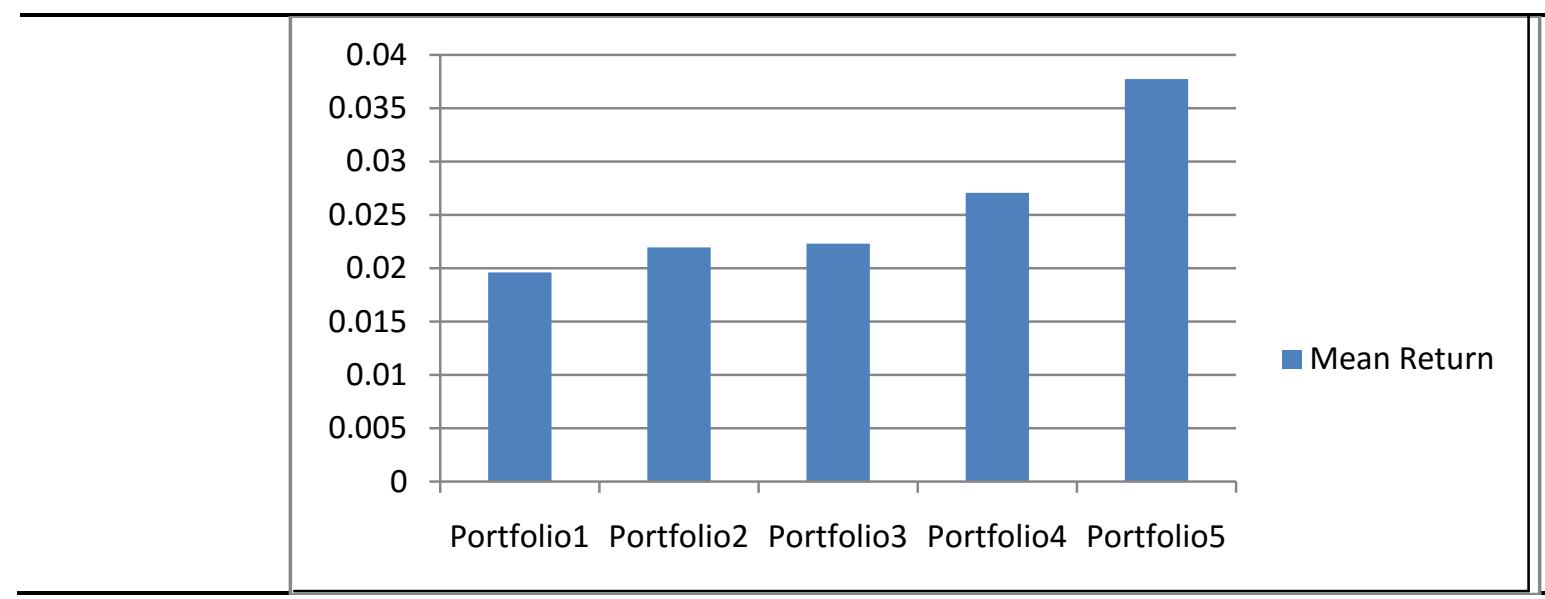

This is consistent with risk return trade off, i.e., higher risks are associated with high potentials returns. The mean portfolio excess returns is increasing consistently from portfolio $1(1.96 \%)$ to portfolio 5 $(3.77 \%)$.

There are some months where low volatility quintile yields higher returns but in most of the cases high volatility portfolio outperforms low volatility portfolio.

Next we check if the returns on volatility sorted portfolios can be explained by the Capital Asset Pricing Model. To test CAPM we run the regression equation (1). Regression results are shown in table II.

Table II: CAPM Regression: $\left(r_{p t}-r_{f t}\right)=\alpha+\beta\left(r_{m t}-r_{f t}\right)+e_{t}$

The table II gives results of CAPM model where excess returns on volatility sorted portfolios are regressed on the market factor.

\begin{tabular}{|l|l|l|l|l|l|}
\hline & $\boldsymbol{\alpha}$ & $\boldsymbol{\beta}$ & \multicolumn{1}{c|}{$\boldsymbol{t}_{\boldsymbol{\alpha}}$} & $\boldsymbol{t}_{\boldsymbol{\beta}}$ & Adjusted R $^{\mathbf{2}}$ \\
\hline Portfolio 1 & 0.01689 & 0.10924 & 1.29604 & 0.75034 & -0.01937 \\
\hline Portfolio 2 & 0.01178 & 0.20993 & 0.67990 & 2.11835 & 0.13166 \\
\hline Portfolio 3 & 0.01452 & 0.31228 & 0.80971 & 1.55876 & 0.05852 \\
\hline Portfolio 4 & 0.01705 & 0.40262 & 0.82435 & 1.74275 & 0.08136 \\
\hline Portfolio 5 & 0.03133 & 0.45778 & 1.76091 & 1.29713 & 0.02882 \\
\hline
\end{tabular}

The regression results are consistent with our previous table as the value of $\beta$ is increasing in a continuous manner from portfolio 1 (Low volatility portfolio) to portfolio 5 (High volatility portfolio), thus the portfolio 1 has the lowest systematic risk and portfolio 5 has the highest systematic risk. 
This implies that portfolio 1 has lowest total volatility as well as lowest systematic volatility among given portfolios and portfolio 5 has highest total volatility as well as highest systematic volatility among given portfolios. Thus high volatility portfolio yields high return and low volatility portfolio yields low returns. Table 2 also indicates that intercepts are statistically significant at 5\% level for all the portfolios and increasing from portfolio 1 and portfolio 5. Alpha is a measure of abnormal return. Thus high volatility portfolio yields high abnormal return. The significant alpha values imply that CAPM is not a good indicator of asset returns. There may be some other factors which are affecting the returns on volatility sorted portfolios.

\subsection{Summary and Conclusions}

According to various theories and researches, one can get higher returns only by bearing higher risks. However, in this topic we are trying to find out low volatility anomaly in Indian Equity market which is well documented, evidenced and validated in other foreign markets, in which the traditional theory of High risk gets high return and low risk gets low returns get discarded. Regardless of whether we define risk as volatility or beta, low risk securities outperform high risk securities. This is called low risk anomaly.

Using data from January 2001 to December 2014 we attempt to study low volatility anomaly in India. Stock returns are measured monthly on adjusted monthly closing prices of the companies listed in CNX 100 by using the formula $\ln (\mathrm{P} 1 / \mathrm{P} 0)$, where $\mathrm{P} 1$ is the current month's closing stock price and $\mathrm{P} 0$ is previous month's closing stock price.

In this study, risk of a stock or volatility is defined as the standard deviation of monthly returns over a period of 60 months. This period of 60 months is called the estimation period. Then stocks are sorted into quintiles on the basis of trailing volatility. We rebalance portfolios every month and hold them for one month. Monthly returns on these volatility sorted quintiles are observed.

Our empirical analysis shows that high volatility quintile yields high return and vice versa. Average excess returns continuously increasing from lowest volatility portfolio to highest volatility portfolio. Hence, low volatility anomaly does not exist in Indian equity market and our results supports the traditional finance theories. We further regressed to the portfolio returns on excess market returns and find that high volatility portfolios have high beta coefficient and alpha values. In our study, the value of beta and alpha which is abnormal return in CAPM model are monotonically increasing from portfolio 1 to portfolio 5, thus supporting CAPM model and Finally, discarding low volatility anomaly in India.

\subsection{Limitations of the Study}

The following are the limitations of the present study.

1) This study is restricted to Indian Capital Market alone and to only one Index of NSE.

2) This study is based mainly on secondary data.

3) The only publicly available data on closing prices has been used.

4) This study used certain limited statistical tools which have certain inherent limitations.

5) The study did not analyze the other technical anomalies.

6) Resources are limited for the research.

7) Limited to low volatility anomaly with limited period of time.

\subsection{Practical Implications}

Though, the results are quite surprising, as we expected to find low volatility anomaly which could prove that National Stock Exchange is not an efficient market. Nevertheless, further investigation must be conducted and tested before we could reject the hypothesis that low volatility anomaly does not exist in 
Indian Stock Market. Such studies are important with investor's point of view as well as to make the market more efficient. So from this study, it is better for investors to purchase stocks on the basis of their risk taking capacities to get required rate of return with proper time frame.

\subsection{References}

\subsection{Books}

1) Bodie, Z., Kane, A. and Marcus, A.J.,( 2002). Investments. International Edition. New York, Boston, London.

2) Cuthbertson, K. and Nitzsche, D., (2005). Quantitative financial economics: stocks, bonds and foreign exchange. John Wiley \& Sons.

3) Gujarati, D.N., (2012). Basic econometrics. Tata McGraw-Hill Education.

4) Damodaran, A., (2012). Investment valuation: Tools and techniques for determining the value of any asset (Vol. 666). John Wiley \& Sons.

5) Gujarati, D.N. and Porter, D.C., (1999). Essentials of econometrics.

6) Elton, E.J., Gruber, M.J., Brown, S.J. and Goetzmann, W.N., (2009). Modern portfolio theory and investment analysis. John Wiley \& Sons.

7) Gupta, S.P. and Gupta, M.P.,(2010). Business statistics. Sultan Chand \& Sons.

8) Kothari, C.R.,(2004). Research methodology: Methods and techniques. New Age International.

9) Nargundkar, R., (2003). Marketing Research-Text \& Cases 2E. Tata McGraw-Hill Education..

10) Chandra, P., (2011). Financial management. Tata McGraw-Hill Education.

11) Ross S, Westerfield R, Jaffe J., (2005). Corporate Finance. Tata McGraw-Hill Education

12) Sharpe WF, Alexander GJ, Bailey JV.,(1999).Investments.USA:Prentice Hall, Inc.

13) Tsay, R.S., (2005). Analysis of financial time series (Vol. 543). John Wiley \& Sons.

\subsection{Journals}

1) Arman, G., (2010). Low Volatility Equity Portfolios. October, Rogerscasey.

2) Baker, M.P., Bradley, B. and Taliaferro, R., (2013). The Low Beta Anomaly: A Decomposition into Micro and Macro Effects.

3) Baker, M., Bradley, B. and Wurgler, J., (2011). Benchmarks as limits to arbitrage: Understanding the low-volatility anomaly. Financial Analysts Journal, 67(1), pp.40-54.

4) Baker, N.L. and Haugen, R.A.,( 2012). Low risk stocks outperform within all observable markets of the world. Available at SSRN 2055431.

5) Blitz, D. and Van Vliet, P., (2007). The volatility effect: Lower risk without lower return. Journal of Portfolio Management, pp.102-113.

6) Carhart, M.M., (1997). On persistence in mutual fund performance. The Journal of finance, 52(1), pp.57-82.

7) Clarke, R.G., De Silva, H. and Thorley, S., (2006). Minimum-variance portfolios in the US equity market. The Journal of Portfolio Management,33(1), pp.10-24.

8) Fama, E.F. and French, K.R., (1992). The cross-section of expected stock returns. the Journal of Finance, 47(2), pp.427-465.

9) Frazzini, A. and Pedersen, L.H.,(2014). Betting against beta. Journal of Financial Economics, 111(1), pp.1-25.

10) Garg, M.V. and Wadhwa, M.S., Low Volatility Anomaly in India.

11) Lewellen, J., (2014). The cross section of expected stock returns.Forthcoming in Critical Finance Review.

12) Li, X. and Sullivan, R.N., (2010). Why Low-Volatility Stocks Outperform: Market Evidence on Systematic Risk versus Mispricing. working paper, Boston College, CFA Institute.

13) Pettengill, G.N., Sundaram, S. and Mathur, I.,( 1995). The conditional relation between beta and returns. Journal of financial and quantitative analysis,30(01), pp.101-116. 
14) Rambhia, R., Joshipura, M. and Joshipura, N., (2013). Low Risk Anomaly: A New Enemy of Market Efficiency. IUP Journal of Financial Risk Management, 10(3), p.7.

15) Riley, T.B., (2014). Two Essays on the Low Volatility Anomaly.

16) Soe, A.M., (2012). The Low Volatility Effect: A Comprehensive Look.Available at SSRN 2128634.

17) Sudarvel, J. and Velmurugan, R., (2015). Indian Stock Market Anomalies: A Literature Review.

10.3 Websites

1) http://www.nseindia.com/products/content/equities/indices/cnx_100.htm, Accessed on 26/12/2015.

2) http://www.finmin.nic.in/, Accessed on 27/12/2015.

3) https://www.rbi.org.in/, Accessed on 28/12/2015.

4) https://en.wikipedia.org/wiki/Market_anomaly , Accessed on 29/12/2015.

5) http://www.scholar.google.com , Accessed on 29/12/2015.

6) http://www.wikepedia.com , Accessed on 30/12/2015. 